\title{
Predictive Factors Affecting the Maxillary Alveolar Bone Thickness: A Cone-Beam Computed Tomography Study
}

This article was published in the following Dove Press journal: Clinical, Cosmetic and Investigational Dentistry

\author{
Amal Linjawi (D) \\ Orthodontic Department, Faculty of \\ Dentistry, King Abdulaziz University, \\ Jeddah, Saudi Arabia
}

Purpose: Many important structures are associated with the maxillary alveolar bone and should be considered during orthodontic tooth movement. The purpose of this study was to investigate the correlation between the anterior maxillary alveolar bone thickness (AMABT), inclination of the central incisors, and the incisive canal (IC), as well as changes in the thickness based on age and sex of the patients.

Methods: This cross-sectional study was conducted using archived cone-beam computed tomography $(\mathrm{CBCT})$ records categorized according to age and sex. The parameters measured were; $\mathrm{AMABT}$ at three levels: alveolar crest, mid-root, and apex; incisor to palatal plane (Inc/PP) angle and IC width at palatal opening. OnDemand 3D Imaging software was utilized for image reconstruction and measurement. Data were analyzed using linear regression analysis and Mann-Whitney test. A $P$-value of $<0.05$ was considered significant.

Results: Out of the 300 CBCT images assessed, only 135 images ( 70 males and 65 females; age range $=17-63$ years) fulfilled the inclusion criteria. The Inc/PP angle had a significant effect on the AMABT at the alveolar crest and mid-root levels $(P<0.01)$. Width of the IC at palatal opening had a significant effect on AMABT at the mid-root and apex level $(P<0.01)$. Age had a significant effect on AMABT at three levels $(P<0.05)$. Males demonstrated significantly greater AMABT at all levels than females $(P<0.01)$.

Conclusion: There was an association between AMABT and the Inc/PP angle, width of the IC at palatal opening, age, and sex of the patients.

Keywords: CBCT, incisor inclination, maxillary alveolar bone thickness, orthodontic tooth movement, 3D imaging

\section{Introduction}

Orthodontic treatment in adults has increased in recent times, especially with the advent of new techniques and appliances such as clear aligners and mini-screws. ${ }^{1}$ This has mandated changes in the orthodontic treatment modalities and mechanics, as well as the amount and direction of tooth movement. ${ }^{1-4}$ The treatment of deep bite and gummy smile was considered challenging in adult orthodontic patients. ${ }^{2,3}$ Such problems require intrusion of anterior teeth with or without surgical intervention. Vertical anchorage control has been enhanced with advances in miniscrews as skeletal anchorage devices; therefore, it is now possible to achieve true intrusion of maxillary incisors. ${ }^{1,3,4}$ However, any tooth movement or dental procedures in the maxillary anterior region requires careful assessment of multiple surrounding structures such as thickness and quality of the alveolar bone, root of the incisor
Correspondence: Amal Linjawi Orthodontic Department, Faculty of Dentistry, King Abdulaziz University, P.O. Box 80209, Jeddah 21589, Saudi Arabia Email ailinjawi@kau.edu.sa 
in relation to the labial and palatal bone, as well as proximity to the incisive canal (IC). ${ }^{1-5}$ Cone-beam computed tomography (CBCT) enables 3D mapping; therefore, it can be used to obtain true quantitative and highly accurate measurements of the height and thickness of the alveolar bone. $^{6}$

Several studies have reported significant changes in thickness of the maxillary alveolar bone following alterations in the inclination of the maxillary incisors. ${ }^{7-9}$ Moreover, studies have reported variations in the alveolar bone thickness in different malocclusions. ${ }^{8}$ Panda et $\mathrm{al}^{10}$ assessed the association between width of the IC and alveolar bone thickness, and observed a positive correlation between the two. Thus, a specific diagnosis of each case has been recommended before any orthodontic tooth movement. $^{7}$

Studies have also assessed changes in alveolar bone thickness during orthodontic movement of incisor teeth.11,12 Multiple factors have been reported to affect changes in alveolar bone thickness, including rate of tooth movement, changes in inclination, and the extent of movement of the incisors. ${ }^{11,12}$ However, such changes were found to vary at different heights of the alveolar bone. ${ }^{12}$

Based on these findings, the present research aimed to investigate the correlation between the anterior maxillary alveolar bone thickness (AMABT), inclination of the central incisors, and the IC, as well as changes in the thickness based on the age and sex of the patients.

The null hypothesis: there is no significant relationship between the AMABT and inclination of the central incisors, IC width, and age and sex of the patients.

\section{Materials and Methods Study Design}

This was a cross-sectional study conducted using archived CBCT records of patients who were seeking treatment at the Faculty of Dentistry, King Abdulaziz University, Jeddah, Saudi Arabia. The study was approved by the Ethical Committee of the same institution [Ethical no.: 100-06-19] and was conducted in accordance with the Declaration of Helsinki of 1975, as revised in 2008. Written informed consent was obtained from all patients.

\section{Sample Selection}

Archived records of patients $(n=300)$ who underwent CBCT for a variety of orthodontic and non-orthodontic dental problems were screened. Inclusion of CBCT images was based on the following criteria; 1) image of at least the maxilla, 2) no history of orthodontic treatment, 3) no missing or supernumerary maxillary incisors, 4) no prosthodontic or endodontic treatment to the maxillary incisors, 5) no history of trauma to the maxillary incisors, and 6) no congenital anomalies such as cleft lip and palate.

\section{CBCT Images}

All CBCT scans were obtained using the following settings: $1 \mathrm{~mm}$ slice breadth, exposure of $120 \mathrm{kV}, 15 \mathrm{~mA}, 12-$ inch field, and $0.4 \mathrm{~mm}$ voxel size. Image reconstruction and measurement was performed using OnDemand 3D Imaging software (Seoul, Korea).

\section{Parameters Assessed}

The reference points, lines, and measurement variables used in this study followed $\mathrm{Ma}$ et $\mathrm{al}^{8}$ (Figure 1) and Panda et al, ${ }^{10}$ with slight modifications (Figure 2).

For measuring the AMABT and the Inc/PP parameters, the following settings were performed:

(a) Using the axial view at the cementoenamel junction, horizontal and vertical orientation lines were set to intersect in the center of the central incisor (Figure 1A).

(b) Using the coronal view, a vertical orientation line passing through the long axis of the tooth was set (Figure 1B).

(c) A sagittal view was reconstructed with a horizontal line at the cementoenamel junction and a vertical line along the long access of the tooth (Figure 1C).

(d) Using the sagittal reconstruct, the AMABT at alveolar crest, mid-root and apex, as well as the Inc/PP angle were measured (Figure 1D).

The latter measurements were performed as follows;

- The AMABT: determined by drawing a line from the palatal to the labial aspect perpendicular to the long axis of the tooth. The alveolar bone thickness was measured at three levels: alveolar crest, mid-root (equidistant from the alveolar crest and the root apex), and apex (Figure 1D). The AMABT of both the right and left central incisors were measured.

- Inc/PP angle: the PP was derived by connecting the anterior and posterior nasal spines. The angle between the long axis of the central incisor and the palatal plane was then measured representing the Inc/ 

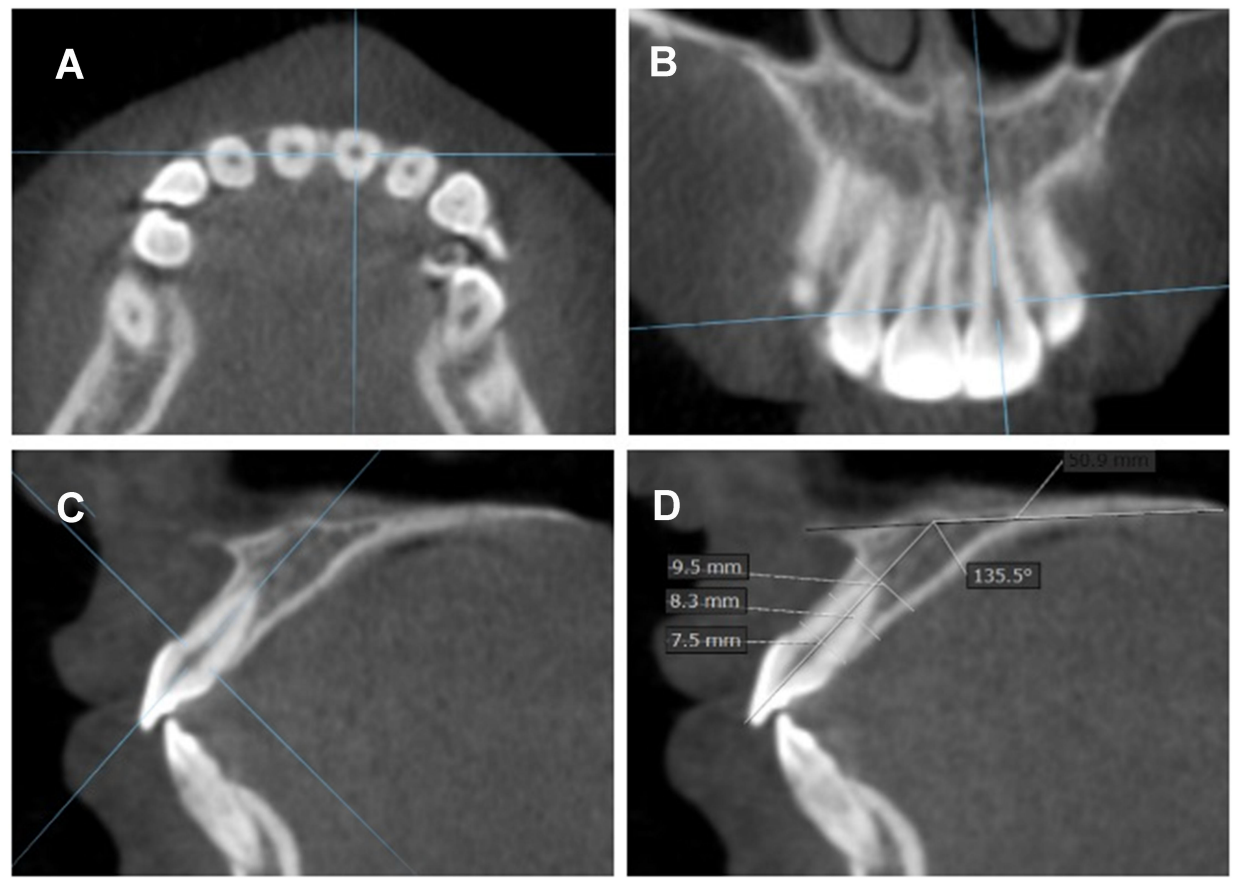

Figure I CBCT Images generated parallel to the tooth axis in the: (A) axial, (B) coronal, and (C) sagittal planes. (D) Sagittal reconstruct showing measurements of the $\mathrm{AMABT}$ at alveolar crest, mid-root, and apex, as well as the Inc/PP angle.
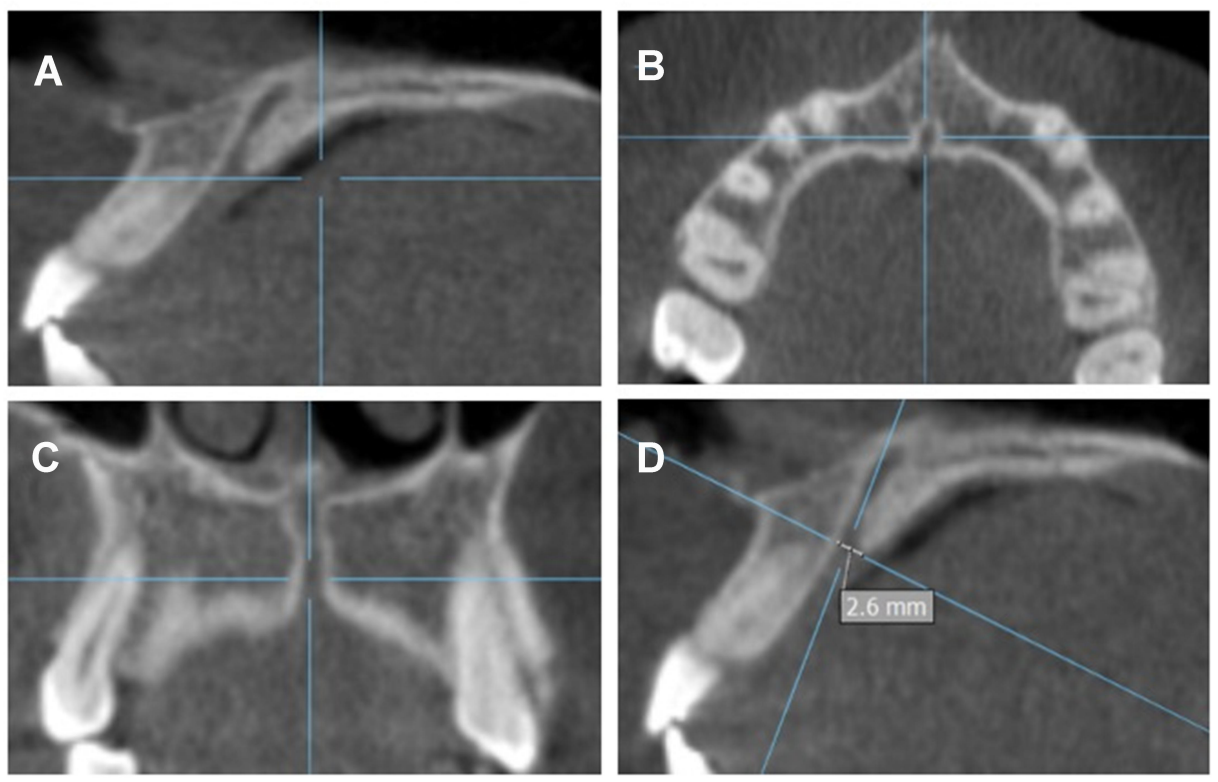

Figure 2 CBCT Images generated parallel to the IC opening in the: (A) sagittal, (B) axial, and (C) coronal planes. (D) Sagittal reconstruct showing the measurement of the width of $I C$ at the palatal opening measured on the horizontal orientation line.

PP angle (Figure 1D). The Inc/PP of both the right and left central incisors were measured.

For measuring the width of the IC at the palatal opening, the following settings were performed: (a) Using the sagittal view, a horizontal orientation line at IC palatal opening was set (Figure 2A).

(b) Using the axial view, horizontal and vertical orientation lines were adjusted to intersect in the center of the IC opening (Figure 2B). 
(c) Using the coronal view, a vertical orientation line was set in the center and parallel to the IC opening (Figure 2C).

(d) Using the sagittal view, the width of the IC at the palatal opening was measured by drawing a line on the horizontal orientation line and passing labiolingually along the width of the IC (Figure 2D).

Age and sex of the patients were also recorded.

\section{Measurement Error}

One trained examiner performed all the measurements in order to minimize variation in accuracy. Intra-examiner error was calculated by repeating the measurements within a 2-week interval on 10 randomly selected subjects. The intra-examiner reliability was then computed using the intra-class correlation coefficient.

\section{Statistical Analysis}

Descriptive statistics were conducted and presented as means and standard deviations. Associations between the AMABT Inc/PP angle, width of the IC at the palatal opening as well as age were assessed using linear regression analysis. Correlation with sex was assessed using the Mann-Whitney $U$-tests. The obtained data were tabulated in Excel and statistical analysis at 95\% confidence level was performed with SPSS (IBM SPSS statistics for Windows, version 22.0, IBM Corp., Armonk, NY).

\section{Results}

Out of the 300 images assessed, only 135 archived CBCT images fulfilled the inclusion criteria ( 70 males and 65 females). A very high intra-examiner correlation $(\mathrm{r}=0.940)$ was computed for all the assessed parameters. The age of the patients ranged from 17-63 years with a mean of 34.08 \pm 13.79 years.

Table 1 presents the mean and standard deviations for the measured parameters; AMABT at the alveolar crest, mid-root, and apex, Inc./PP angle, and width of the IC at the palatal opening.

Table 2 presents the association between the Inc/PP angle and the AMABT at the three levels assessed. Results showed that the Inc/PP angle had a significant effect on the AMABT at the alveolar crest and mid-root levels $(P<0.01)$. The effect was positive at the crest and negative at the mid-root level. However, the adjusted $\mathrm{R}^{2}$ indicated a weak correlation between the Inc/PP angle and the AMABT $\left(r^{2}=0.034\right)$.
Table 3 presents the association between the width of the IC at the palatal opening and the AMABT at the three levels assessed. Results showed that the width of the IC at the palatal opening had a significant effect on the AMABT at the mid-root and apex levels $(P<0.01)$. The effect was positive at the midroot level and negative at the apex level. However, the adjusted $\mathrm{R}^{2}$ indicated a weak correlation between the width of the IC at the palatal opening and the AMABT $\left(\mathrm{r}^{2}=0.089\right)$.

Table 4 presents the association between age and the AMABT at the three levels assessed. Results showed that age had a significant effect on the AMABT at the three levels $(P<0.05)$. The effect was positive at the mid-root level and negative at the crest and apex levels. However, the adjusted $\mathrm{R}^{2}$ indicated a weak correlation between the two parameters $\left(\mathrm{r}^{2}=0.062\right)$.

Table 5 presents the sex-related differences in the AMABT at the three levels assessed. Males demonstrated significantly greater AMABT at the three levels $(P<0.01)$ compared to females.

\section{Discussion}

The maxillary anterior bone is thin and plays a pivotal role in the decision-making regarding movement of the incisors in the anteroposterior and vertical dimensions. It is also related to some anatomical structures such as the incisor teeth and the IC. The current study investigated the correlation between the AMABT, inclination of the central incisors, and IC, as well as changes in the thickness based on age and sex of the patients.

Similar to the findings of Nahás-Scocate et al, ${ }^{5}$ results of the current study showed that the alveolar bone thickness was greater at the apex level followed by the mid-root and the alveolar crest levels.

Results of the current study indicated that the inclination of the incisors had a significant effect on the thickness of the alveolar bone. The result was in accordance with that reported by Nahm et $\mathrm{al}^{7}$ who found that the alveolar bone

Table I Descriptive Results of the Assessed Parameters ( $n=\mid 35)$

\begin{tabular}{|l|l|l|}
\hline & Mean & Standard Deviation \\
\hline AMABT at alveolar crest $(\mathrm{mm})$ & $5.8 \mathrm{I}$ & 1.02 \\
AMABT at mid-root $(\mathrm{mm})$ & 6.26 & 1.14 \\
AMABT at apex $(\mathrm{mm})$ & 6.74 & 1.50 \\
Inc./PP angle $(\mathrm{mm})$ & 116.19 & 8.78 \\
IC width at palatal opening & 3.83 & 1.10 \\
Age (range: 17-63 years old) & 34.08 & 13.79 \\
\hline
\end{tabular}

Abbreviations: AMABT, anterior maxillary alveolar bone thickness; Inc/PP, incisor to palatal plane angle; IC, incisive canal. 
Table 2 Association Between Inc/PP Angle and the AMABT at Three Levels $(n=135)$. Significance Level is Set at $P<0.05$

\begin{tabular}{|l|l|l|l|l|l|l|l|}
\hline \multirow{2}{*}{ Dependent Variable: Inc/PP } & \multicolumn{2}{|l|}{ Unstandardized Coefficients } & Standardized Coefficients & \multirow{t}{*}{ Sig. } & \multicolumn{2}{|l|}{ 95\% Confidence Interval for B } \\
\cline { 2 - 4 } \cline { 6 - 8 } & B & Std. Error & Beta & & & Lower Bound & Upper Bound \\
\hline (Constant) & 112.504 & 3.680 & & 30.570 & 0.000 & 105.246 & 119.762 \\
AMABT at alveolar crest & 2.850 & 0.991 & 0.332 & 2.874 & $0.004 * *$ & 0.894 & 4.805 \\
AMABT at mid-root & -3.230 & 1.166 & -0.419 & -2.771 & $0.006 * *$ & -5.529 & -0.932 \\
AMABT at apex & 1.089 & 0.654 & 0.187 & 1.665 & 0.097 & -0.201 & 2.379 \\
\hline
\end{tabular}

Notes: Dependent variable: Inc/PP (incisor to palatal plane) angle. Predictors: (constant), AMABT at alveolar crest, AMABT at mid-root, AMABT at apex. Significance level: $* * P<0.01$. Adjusted $\mathrm{R}^{2}=0.034$.

Abbreviation: AMABT, anterior maxillary alveolar bone thickness.

Table 3 Association Between Width of the IC at the Palatal Opening in the Sagittal View and the AMABT at Three Levels ( $\mathrm{n}=135)$. Significance Level is Set at $P<0.05$

\begin{tabular}{|c|c|c|c|c|c|c|c|}
\hline \multirow[t]{2}{*}{ Dependent Variable: IC } & \multicolumn{2}{|c|}{$\begin{array}{l}\text { Unstandardized } \\
\text { Coefficients }\end{array}$} & \multirow{2}{*}{$\begin{array}{l}\text { Standardized Coefficients } \\
\text { Beta }\end{array}$} & \multirow[t]{2}{*}{$\mathbf{t}$} & \multirow[t]{2}{*}{ Sig. } & \multicolumn{2}{|c|}{ 95\% Confidence Interval for B } \\
\hline & B & Std. Error & & & & Lower Bound & Upper Bound \\
\hline (Constant) & 2.308 & 0.447 & & 5.165 & 0.000 & 1.427 & 3.190 \\
\hline AMABT at alveolar crest & 0.106 & 0.120 & 0.099 & 0.884 & 0.378 & -0.131 & 0.344 \\
\hline AMABT at mid-root & 0.392 & 0.142 & 0.407 & 2.771 & $0.006 * *$ & 0.113 & 0.672 \\
\hline AMABT at apex & -0.230 & 0.079 & -0.315 & -2.895 & $0.004 * *$ & -0.387 & -0.073 \\
\hline
\end{tabular}

Notes: Dependent variable: width of the IC (incisive canal) at the palatal opening in the sagittal view. Predictors: (constant), AMABT at alveolar crest, AMABT at mid-root, AMABT at apex. Significance level: $* * P<0.01$. Adjusted $R^{2}=0.089$.

Abbreviation: AMABT, anterior maxillary alveolar bone thickness.

Table 4 Association Between Age and the AMABT at Three Levels $(n=135)$. Significance Level is Set at $P<0.05$

\begin{tabular}{|c|c|c|c|c|c|c|c|}
\hline \multirow[t]{2}{*}{ Dependent Variable: Age } & \multicolumn{2}{|c|}{$\begin{array}{l}\text { Unstandardized } \\
\text { Coefficients }\end{array}$} & \multirow{2}{*}{$\begin{array}{l}\text { Standardized Coefficients } \\
\text { Beta }\end{array}$} & \multirow[t]{2}{*}{$\mathbf{t}$} & \multirow[t]{2}{*}{ Sig. } & \multicolumn{2}{|c|}{$95 \%$ Confidence Interval for B } \\
\hline & B & Std. Error & & & & Lower Bound & Upper Bound \\
\hline (Constant) & 41.955 & 5.693 & & 7.369 & 0.000 & 30.726 & 53.183 \\
\hline AMABT at alveolar crest & -3.693 & 1.534 & -0.274 & -2.408 & $0.017^{*}$ & -6.718 & -0.668 \\
\hline AMABT at mid-root & 5.947 & 1.803 & 0.491 & 3.298 & $0.00 I^{* *}$ & 2.390 & 9.503 \\
\hline AMABT at apex & -3.506 & 1.012 & -0.382 & -3.465 & $0.001 * *$ & -5.501 & -1.510 \\
\hline
\end{tabular}

Notes: Dependent variable: age. Predictors: (constant), AMABT at alveolar crest, AMABT at mid-root, AMABT at apex. Significance level: $* P<0.05, * * P<0.01$. Adjusted $\mathrm{R}^{2}=0.062$.

Abbreviation: AMABT, anterior maxillary alveolar bone thickness.

was very thin in patients with skeletal Class I bimaxillary protrusion. Similarly, Ma et $\mathrm{al}^{8}$ reported that maxillary anterior alveolar bone was thinner in patients with skeletal Class II than Class III relationships. The current study also identified that the inclination of the incisors had a positive effect on alveolar bone level at the crest and a negative effect at the mid-root level. This finding was similar to that of NahásScocate et $\mathrm{al}^{5}{ }^{5}$ who reported a positive correlation between the inclination of the incisors and the alveolar bone width. Tian et $\mathrm{al}^{9}$ also reported that alveolar bone thickness of lingually inclined maxillary incisors was less at the root apex than normal and labially inclined incisors.
Some studies investigated the changes in the maxillary anterior alveolar bone associated with different types of tooth movement. ${ }^{11,12}$ Yodthong et $\mathrm{al}^{11}$ found that the changes in alveolar bone thickness of maxillary incisors during retraction were significantly affected by the rate of tooth movement, changes in inclination, and the amount of intrusion. They also observed that thickness of the labial bone increased while that of the palatal bone decreased during incisor retraction. ${ }^{11}$ In contrast, Thongudomporn et $\mathrm{al}^{12}$ found that the hickness of the alveolar bone in the maxillary incisor region was significantly affected by proclination and extrusion of the tooth. 
Table 5 Sex-Related Differences in the AMABT at Three Levels. Significance Level is Set at $P<0.05$

\begin{tabular}{|c|c|c|c|c|c|}
\hline & & $\mathbf{N}$ & Mean & Standard Deviation & $P$-value \\
\hline \multirow[t]{3}{*}{ AMABT at alveolar crest $(\mathrm{mm})$} & Male & 70 & 6.04 & 0.93 & $0.002 * *$ \\
\hline & Female & 65 & 5.59 & 1.08 & \\
\hline & Total & 135 & 5.81 & 1.02 & \\
\hline \multirow[t]{3}{*}{ AMABT at mid-root (mm) } & Male & 70 & 6.61 & 1.22 & $0.000 * * *$ \\
\hline & Female & 65 & 5.91 & 0.95 & \\
\hline & Total & 135 & 6.26 & 1.14 & \\
\hline \multirow[t]{3}{*}{ AMABT at apex $(\mathrm{mm})$} & Male & 70 & 7.26 & 1.71 & $0.000 * * *$ \\
\hline & Female & 65 & 6.22 & 1.06 & \\
\hline & Total & 135 & 6.74 & 1.50 & \\
\hline
\end{tabular}

Note: Significance level: $* * P<0.01, * * * P<0.001$.

Abbreviation: AMABT, anterior maxillary alveolar bone thickness.

The study reported significant reduction in the palatal and total bone thickness, while that of the labial bone was not significantly affected by proclination and extrusion of the tooth. ${ }^{12}$

Similar to the findings of other studies, the width of IC and age and sex of the patients had significant effects on the thickness of the alveolar bone. ${ }^{10-15}$ Males demonstrated significantly greater alveolar bone thickness at the levels assessed compared to females. ${ }^{10-14}$

The current study supports other findings in that a specific diagnosis by $\mathrm{CBCT}$ of each case that requires dentoalveolar procedures in the maxillary anterior region is recommended. ${ }^{7,16-19}$ This includes any surgical procedures, implants, and miniscrew insertion, as well as orthodontic movement of anterior teeth in severe cases. $^{7,16-19}$

Miniscrews are gaining importance in the management of complex orthodontic tooth movement. ${ }^{16-19}$ Their position and site of placement of miniscrews has been studied and safe zones have been recommended for their placement as well as stability. ${ }^{17-19}$

\section{Conclusion}

The current study found an association between changes in the AMABT and the Inc/PP angle, width of the IC at the palatal opening, and age and sex of the patients.

\section{Funding}

This research received no external funding.

\section{Disclosure}

The author declares no conflicts of interest in this work.

\section{References}

1. Saxena R, Kumar PS, Upadhyay M, Naik V. A clinical evaluation of orthodontic mini-implants as intraoral anchorage for the intrusion of maxillary anterior teeth. World J Orthod. 2011;11(4):346-351.

2. Al-Falahi BA, Hammad SM, El-Kenawy MH, Fouda MA. Intrusion of maxillary incisors by mini-screw anchorage of Angle Class II division 2 malocclusion cases. Int J Orthod Milwaukee. 2012;23(4):29-35.

3. Silberberg N, Goldstein M, Smidt A. Excessive gingival displayetiology, diagnosis, and treatment modalities. Quintessence Int. 2009;40(10):809-818.

4. Kaku M, Kojima S, Sumi H, et al. Gummy smile and facial profile correction using miniscrew anchorage. Angle Orthod. 2012;82 (1):170-177. doi:10.2319/020711-86.1

5. Nahás-Scocate AC, de Siqueira Brandão A, Patel MP, LipiecXimenez ME, Chilvarquer I, Do Valle-Corotti KM. Bone tissue amount related to upper incisors inclination. Angle Orthod. 2014;84 (2):279-285. doi:10.2319/031213-211.1

6. Timock AM, Cook V, McDonald T, et al. Accuracy and reliability of buccal bone height and thickness measurements from cone-beam computed tomography imaging. Am J Orthod Dentofacial Orthop. 2011;140(5):734-744. doi:10.1016/j.ajodo.2011.06.021

7. Nahm KY, Kang JH, Moon SC, et al. Alveolar bone loss around incisors in Class I bidentoalveolar protrusion patients: a retrospective three-dimensional cone beam CT study. Dentomaxillofac Radiol. 2012;41(6):481-488. doi:10.1259/dmfr/30845402

8. Ma J, Huang J, Jiang JH. Morphological analysis of the alveolar bone of the anterior teeth in severe high-angle skeletal Class II and Class III malocclusions assessed with cone-beam computed tomography. PLoS One. 2019;14(3):e0210461. doi:10.1371/journal.pone.0210461

9. Tian YL, Liu F, Sun HJ, et al. Alveolar bone thickness around maxillary central incisors of different inclination assessed with cone-beam computed tomography. Korean J Orthod. 2015;45 (5):245-252. doi:10.4041/kjod.2015.45.5.245

10. Panda M, Shankar T, Raut A, Dev S, Kar AK, Hota S. Cone beam computerized tomography evaluation of incisive canal and anterior maxillary bone thickness for placement of immediate implants. $J$ Indian Prosthodont Soc. 2018;18(4):356-363. doi:10.4103/jips. jips_167_18

11. Yodthong N, Charoemratrote C, Leethanakul C. Factors related to alveolar bone thickness during upper incisor retraction. Angle Orthod. 2013;83(3):394-401. doi:10.2319/062912-534.1

12. Thongudomporn U, Charoemratrote C, Jearapongpakorn S. Changes of anterior maxillary alveolar bone thickness following incisor proclination and extrusion. Angle Orthod. 2014;85(4):549-554. doi:10.2319/051614-352.1 
13. Lee JE, Jung CY, Kim Y, Kook YA, Ko Y, Park JB. Analysis of alveolar bone morphology of the maxillary central and lateral incisors with normal occlusion. Medicina (Kaunas). 2019;55(9).

14. Uner DD, Izol BS, Gorus Z. Correlation between buccal and alveolar bone widths at the central incisors according to cone-beam-computed tomography. Niger J Clin Pract. 2019;22(1):79-84. doi:10.4103/njcp. njcp_320_18

15. Zhou Z, Chen W, Shen M, Sun C, Li J, Chen N. Cone beam computed tomographic analyses of alveolar bone anatomy at the maxillary anterior region in Chinese adults. $J$ Biomed Res. 2014;28 (6):498-505. doi:10.7555/JBR.27.20130002

16. Leung MT, Lee TC, Rabie AB, Wong RW. Use of miniscrews and miniplates in orthodontics. J Oral Maxillofac Surg. 2008;66(7):14611466. doi:10.1016/j.joms.2007.12.029
17. Poggio PM, Incorvati C, Velo S, Carano A. "Safe zones": a guide for miniscrew positioning in the maxillary and mandibular arch. Angle Orthod. 2006;76(2):191-197. doi:10.1043/0003-3219(2006)076 [0191:SZAGFM]2.0.CO;2

18. Ohiomoba H, Sonis A, Yansane A, Friedland B. Quantitative evaluation of maxillary alveolar cortical bone thickness and density using computed tomography imaging. Am J Orthod Dentofacial Orthop. 2017;151(1):82-91. doi:10.1016/j.ajodo.2016.05.015

19. Pan F, Kau CH, Zhou H, Souccar N. The anatomical evaluation of the dental arches using cone beam computed tomography-an investigation of the availability of bone for placement of mini-screws. Head Face Med. 2013;9:13. doi:10.1186/1746-160X-9-13.

\section{Publish your work in this journal}

Clinical, Cosmetic and Investigational Dentistry is an international, peer-reviewed, open access, online journal focusing on the latest clinical and experimental research in dentistry with specific emphasis on cosmetic interventions. Innovative developments in dental materials, techniques and devices that improve outcomes and patient satisfaction and preference will be highlighted. The manuscript management system is completely online and includes a very quick and fair peer-review system, which is all easy to use. Visit http://www.dovepress.com/testimonials.php to read real quotes from published authors. 